\title{
Morphopathological changes of dendrites in experimental animals and in human nervous diseases
}

\begin{abstract}
The present review describes the pathological changes of shaft dendrites in most central nervous diseases. We have illustrated most pathological changes using cortical biopsies of patients with congenital hydrocephalus, severe and complicated traumatic brain injuries, and brain tumors. Swollen and beaded dendrites exhibit fragmentation of limiting plasma membrane, cytomembranes and cytoskeletal structures. The swollen dendrites show vacuolization, dense residual bodies, enlarged rough and smooth endoplasmic reticulum, edematous clear and dark mitochondria. The multifactorial processes associated with brain edema and brain ischemia, such as calcium overload, activation of calciumdependent proteolitic enzymes, protein aggregation, glutamate-induced neurotoxicity, release of lysosomal enzymes, deficit of ATP, stress oxidative and lipid peroxidation have been considered in relation with pathological dendritic changes. Dendrotoxicity due to brain edema and brain ischemia seems to be the fundamental pathogenetic mechanism underlying the dendritic damage.
\end{abstract}

Keywords: dendrites, brain edema, brain trauma, hydrocephalus, brain tumors, electron microscopy
Volume 9 Issue 2 - 2019

\section{Orlando J Castejón}

Department Biological Research Institute Faculty of Medicine, Zulia University,Venezuela

Correspondence: Orlando J Castejón. Institute of Biological Research "Drs. Orlando Castejón and Haydee Viloria de Castejón”. School of Medicine. University of Zulia. Section 526 Maracaibo,Venezuela, Email ocastejo@gmail.com

Received: February 22, 2019 | Published: April 24, 2019

\section{Introduction}

Dendritic development and arborisation show aberrant or anomalous patterns in aging process and in various central nervous system diseases, such as brain trauma, schizophrenia, neurodegenerative diseases, epilepsy, malnutrition in developing brain, infections, mental retardation, hydrocephalus, cerebral ischemia, and exposure to alcohol and other toxins. ${ }^{1-48}$ The formation of meganeurites in human neuronal storage diseases, ${ }^{4,8}$ the existence of more branched dendrites in neuronal elderly individuals, ${ }^{49,50}$ and the appearance of new dendritic growths in Alzheimer disease, ${ }^{1}$ reveal that the adult human neuronal system appears capable of responding to various stimulus, and exhibits the potential to modify existing neuronal connections. Abnormal dendritic development and dendritic spine "dysgenesis" have been reported in mental retardation, ${ }^{28,51,52}$ and severe protein-calorie malnutrition. ${ }^{27}$ Aberrant dendritic growth and aberrant patterns of spine morphology have been reported by Machado-Salas ${ }^{53}$ in Bourneville's disease. Marked atrophy of basal and apical dendrites of neurons of layer 3 and 5 of cerebral cortex in Tay-Sachs disease was reported by Takashima et al. ${ }^{12}$ Loss of Purkinje cell spines, cactus-like thickenings and atrophy of Purkinje cell dendrites may be found in Menke's disease,$^{51}$ and in experimental encephalopathy induced by chronic application of valproate. ${ }^{36}$ Abnormalities of dendritic arborization have been observed by light microscopy in a variety of cerebral malformation, such as microgiria and lisencephaly. ${ }^{10}$

In epilepsy a wide spectrum of dendritic pathology has been recognized, such as loss of dendritic spine and development of nodular or fusiform enlargements along the dendritic shafts. ${ }^{55-57}$ Dendritic abnormalities have been also described in normal aging and various dementias.,50 Normal elderly individuals have longer and more branched dendrites than younger and senile dementia patients. ${ }^{4,58,59}$ Abnormal dendrites have been also found in Huntington's disease. ${ }^{60}$ Age-related regulation of dendritic endocytosis was reported by Blanpied et al. ${ }^{61}$ Castejón \& Arismendi ${ }^{23}$ described swollen and beaded dendrites, disrupted of limiting plasma membrane and cytoskeletal structures in the human edematous cerebral cortex associated to brain trauma, congenital malformations, and brain tumors. Works et al. ${ }^{62}$ reported age-dependent dendritic atrophy of basilar dendrites in the rat nucleus magnocellularis related with loss of cholinergic innervation. Vega et al.$^{63}$ described increased dendritic length, and decreased density of synaptic spines in the prefrontal cortex of rat with renovascular hypertension. Allred and Jones (2004) found dendritic structural plasticity after unilateral ischemic damage of rat sensory motor cortex. Wedzony et al.$^{64}$ reported diminished length of basilar dendrites of prefrontal pyramidal neurons in adult rats after blockade of NMDA receptors in the postnatal period. Rensing et al. ${ }^{65}$ (described dendritic swelling and loss of spines during electrographic seizures induced by 4-aminopyridine in transgenic mice. Peyghambari et al. ${ }^{46}$ found a significant reduction in the length of most dendrites in the axotomized motoneurons of the spinal cord in newborn rats. Radley et al. ${ }^{66}$ encountered reversible apical dendritic retraction in the rat medial prefrontal cortex following repeated stress. Brown et al. ${ }^{67}$ also found remodelling of apical dendrites, atrophy of distal branches, and sparing of proximal branches induced by stress in medial prefrontal cortex. Flores et al. ${ }^{47}$ reported decreased length of basilar dendrites in post-puberal rats after nenonatal excitotoxis lesions of the ventral hippocampus. Zaja-Millatovics et al. ${ }^{68}$ demonstrated shortened dendritic length of neostriatal medium spiny neurons in Parkinson disease. Ishikura et al. ${ }^{69}$ described dendritic atrophy in prion disease. Dierssen \& Ramakers ${ }^{70}$ emphasized the dendritic pathology in mental retardation from the genetic point of view. Shimada et al. ${ }^{71}$ studying a model of cerebral degeneration, the ageing SAMP10 mouse, described age- related dendritic retraction in the entire cerebral cortex and olfactory bulb. Brief exposure to excitotoxic agonists can result in substantial loss of the microtubuleassociated protein MAP2 from neuronal dendrites, and accumulation in neuronal somata. A possible mechanism underling MAP2 loss is 
the activation of the calcium-dependent protease calpain by excessive dendritic Ca2+-loading. ${ }^{72}$

Dlugos $^{73}$ reported smooth endoplasmic reticulum dilation and degeneration in Purkinje neuron dendrites of aging ethanol-fed female rats. Baloyannis et al. ${ }^{74}$ describe substantial alteration of dendritic arborisation in the acoustic cortex in Alzheimer's disease.

In instances of CNS injury or disease, increased concentrations of extracellular glutamate can result in the over-activation of ionotropic glutamate receptors and trigger neuronal cell death (termed excitotoxicity). Two early hallmarks of such neuronal toxicity are mitochondrial dysfunction (depolarization, decreased ATP synthesis, structural collapse and potential opening of the permeability transition pore) and the formation of focal swellings (also termed varicosities/ beads) along the length of the dendrites. ${ }^{75}$

Dlugos ${ }^{73}$ reported dilation of the smooth endoplasmic reticulum (SER), and the formation of degenerating bodies within Purkinje neuron dendrites of aging ethanol-fed female rats, According to this Author, dilation of the SER and the formation of degenerating bodies may be a predictor of dendritic regression. Shansky \& Morrison $^{76}$ reviewed the stress-induced dendritic remodeling in the medial prefrontal cortex (mPFC), with particular focus on new findings that illuminate modulators of these effects. Compression instantly twisted the microtubules and deformed the membrane contour of dendritic trunks, and immediately reduced dendritic spines on the entire dendritic arbor. Liu et al. ${ }^{77}$ reviewed the dendritic changes that have been recorded in neurodegenerative processes including those occurring in development, ageing and diseases. The findings suggest that dendritic pathology is an early sign in disease and underline the importance of synapto-dendritic structure, providing new insights into therapeutic strategies.

Deng et al. ${ }^{78}$ made the characterization of dendritic morphology and neurotransmitter phenotype of thoracic descending propriospinal neurons after complete spinal cord transection and GDNF treatment. Deng \& Reiner $^{78}$ found reductions in dendritic branching and thalamostriatal input in cholinergic interneurons in the Q140 knockin mouse model of Huntington's disease.

Tau protein in dendrites and synapses has been recently implicated in synaptic degeneration and neuronal malfunction. Chronic stress, a well-known inducer of neuronal/synaptic atrophy, triggers hyperphosphorylation of Tau protein and cognitive deficits. Exposure to chronic stress resulted in atrophy of apical dendrites and spine loss in the prefrontal cortex (PFC) neurons. Tau may exert its effects through synaptic mitochondria. ${ }^{79}$ Nava et al ${ }^{80}$ described the temporal dynamics of acute stress-induced dendritic remodeling in medial prefrontal cortex and the protective effect of desipramine. These authors found significant atrophy of apical dendrites at 1day, which was prevented by chronic desipramine, and at 14days after stress exposure.

Saberi et al. ${ }^{81}$ reported dendritic-like aggregates in the motor cortex that co-localized with pTDP-43 and their repeat RNAs dipeptide repeat proteins (DPRs) in amyotrophic lateral sclerosis.

In the present review we describe the structural changes of dendrites in different esperimental and human central nervous system diseases, and we analyze at submicroscopic level the dendritic morphological changes of nerve cells in the edematous human cerebral cortex associated to congenital hydrocephalus, brain trauma, and brain tumors in an attempt to provide better insight on the pathological changes induced by these distinct nosological entities, and the associated brain ischemia.

\section{Submicroscopic changes of dendrites in congenital hydrocephalus.}

The immature hydrocephalic cerebral cortex neuropil in neonate patients with congenital hydrocephalus shows irregularly beaded shaped, and swollen and vacuolated dendritic processes with elongated and dark mitochondria. Most patients with congenital hydrocephalus exhibit lamellipodic and filopodic dendritic processes, and endocytic vesicle formation at the limiting plasma membrane, ${ }^{82}$ These dendrites exhibit mushroom, stubby and filopodic types of dendritic spines making asymmetric synaptic junctions (Figure 1). ${ }^{83}$ Some dendritic processes show fragmented plasma membrane in areas of severe brain hydrocephalic edema (Figure 2).

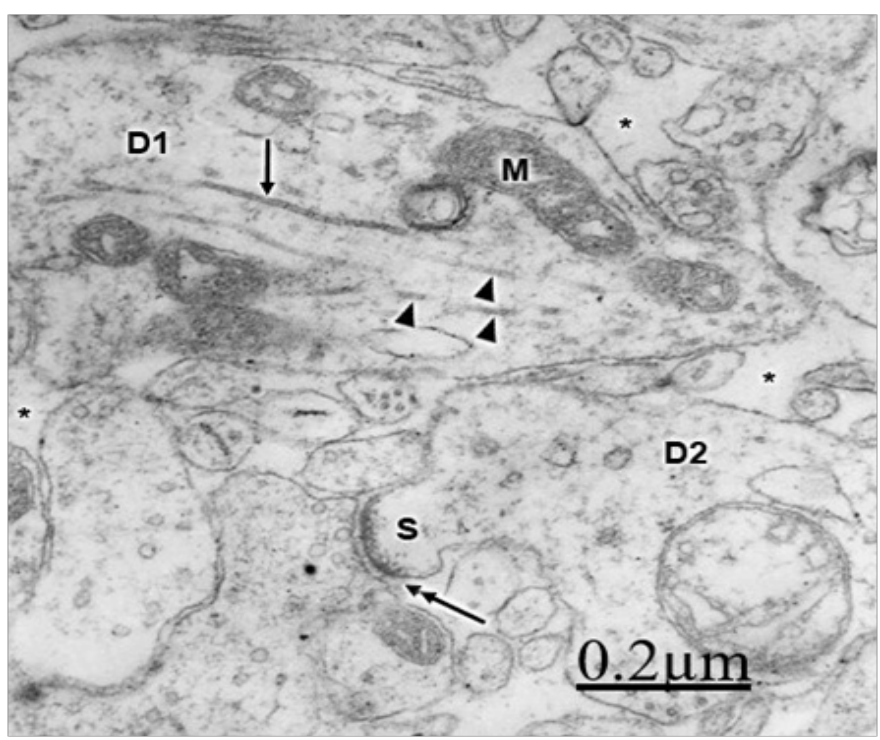

Figure I Arnold-Chiari malformation and communicant hydrocephalus. Neuropil of a I0days-old neonate. Right parietal cortex.

High magnification of a swollen and clear dendrite (DI) exhibiting dark swollen mitochondria (M) with clear dilated cristae, and intact (long arrow) and few fragmented microtubules (arrowheads).A neighbouring clear dendrite (D2) shows an asymmetric synaptic contact (double head arrow) by means of mushroom type-dendritic spine (S). The asterisks label the enlarged extracellular space. $\times 50.000$.

Mc Allister et al. ${ }^{84}$ reported dendritic varicosities and spine loss as the most striking dendritic alterations in experimental induced hydrocephalus in newborn rats. Harris et al. ${ }^{85}$ found a decreased in the total length of dendritic tree in the infant H-TX rats. Hydropic dendritic deterioration has been reported in feline-infantile hydrocephalus by Kreibel \& McAllister. ${ }^{30}$

\section{Dendrite pathology in human traumatic brain injuries}

In patients with traumatic brain injuries exhibiting contusions and associated subdural or extradural hematoma or hygroma, varicose swollen dendrites with fragmented plasma membranes, disruption of cytoskeletal structures characterized by disintegrated microtubules and neurofilaments, electron lucid and vacuolated dendroplasm, enlarged rough and smooth endoplasmic reticulum, partial loss of dendritic spines, increased vesicular transport of microvesicles, dense round and elongated inclusion bodies, and complex or clathrin-coated vesicles are observed (Figure 2) (Figure 3). 


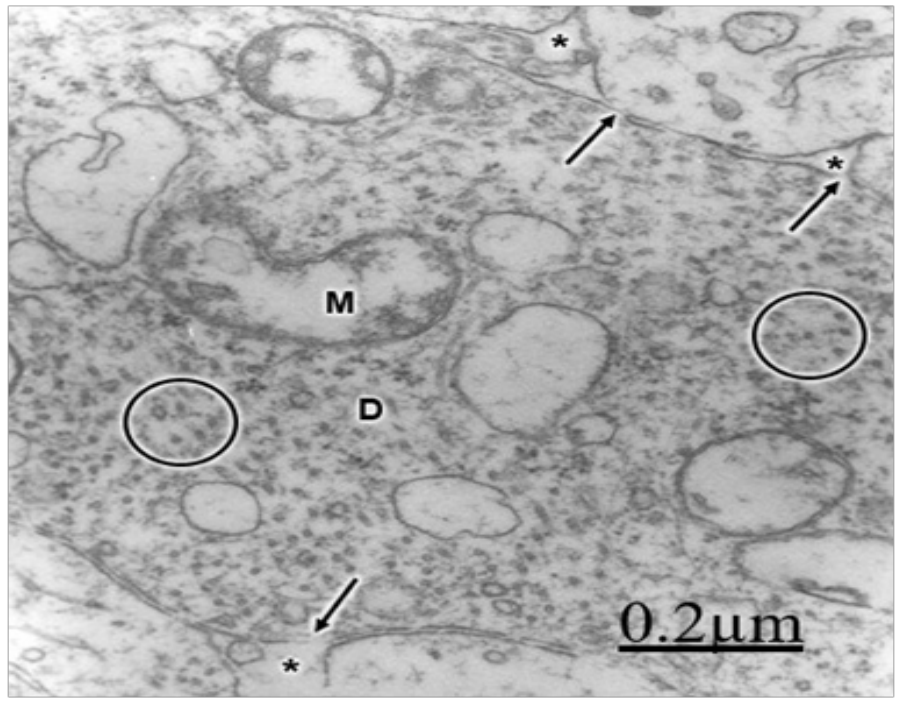

Figure 2 Congenital hydrocephalus associated with lumbar meningomielocele. Right parietal cortex.

Neuropil of a 12days-old neonate showing the longitudinal section of an edematous dendritic process (D) showing a clear dendroplasm, swollen mitochondrion (M), cross sectioned microtubules and neurofilaments (circles). The long arrows label the disrupted dendritic plasma membrane. Note the dilated extracellular space (asterisks) surrounding the dendritic profile that features hydrocephalus interstitial edema. X 45.000 .

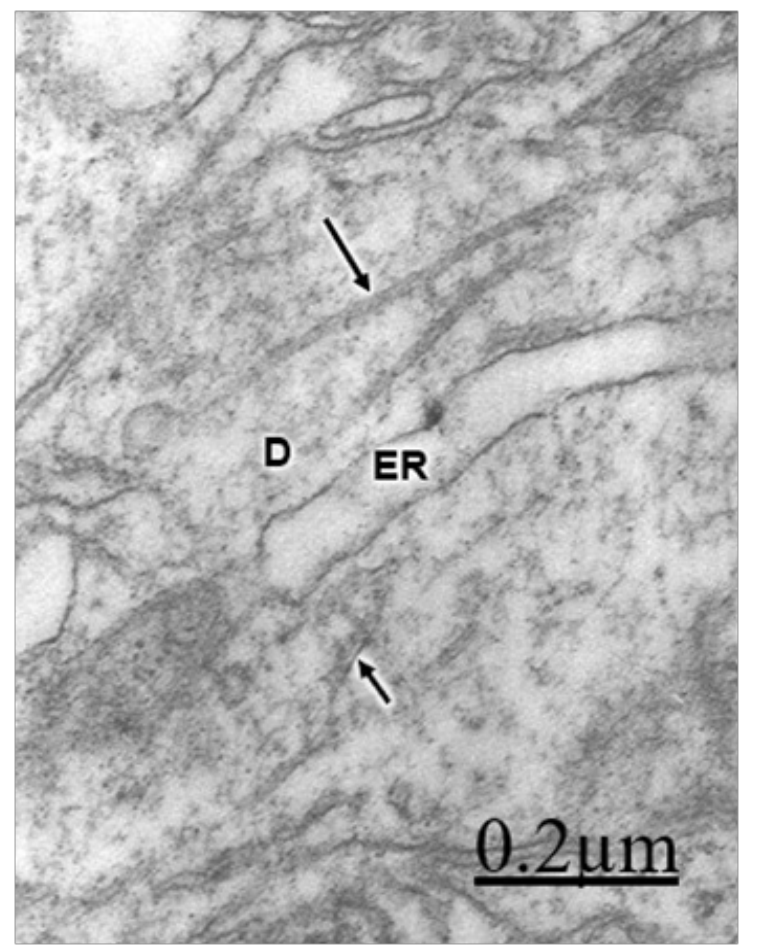

Figure 3 Brain trauma. Severe contusion of frontal region. Left frontal cortex.

Swollen shaft dendritic segment (D) displaying dilated smooth endoplasmic reticulum cisterns (ER), and intact (long arrow) and fragmented

Dendritic angulations, and nodular or segmentary dendritic swelling were earlier reported by Vaquero et al.55, Gallyas \& Zoltay ${ }^{13}$ and Swann et al. ${ }^{31}$ in human epileptic dendrites. According to Vaquero et al. ${ }^{55}$ the nodular dendritic swellings are due to alteration in the microtubular arrangement. Vacuolated dendrites inducing hydropic deterioration and degeneration of dendrites have been reported by Goldstein et al. ${ }^{6}$ in rat central nervous system after ethanol consumption, by Posmantur et al. ${ }^{86}$ after traumatic brain injury in rats, and by Sobaniec-Lotowska ${ }^{36}$ in rat experimental encephalopathy induced by valproate. Saito et al. ${ }^{87}$ found calcium accumulation in swollen dendrites following cerebral ischemia and traumatic brain injury. Gallyas \& Zoltay ${ }^{13}$ considered that in cases of head injury, the beaded appearance of dendritic and axonal processes indicates an advanced stage of morphopathological damage. In addition, some neurons exposed to hypothermia, NMDA or ionophore also developed beaded dendrites (Emery and Lucas, 1995). Focal dendritic swelling was observed by Ferrer et al. (1998) in mucopolysaccharidoses types I, II and III. The focal swelling of dendrites is apparently similar to that observed in axonal processes also due to destruction of cytoskeletal network. ${ }^{88,89}$ Swollen and beaded dendrites have been widely reported in a large variety of pathological entities. Dendritic swelling was observed in stroke-prone spontaneously hypertensive rats, ${ }^{5}$ following intrathecal infusion of $\mathrm{N}$-methyl-D-aspartate, ${ }^{90,91}$ in rats with neuroleptic-induced dyskinesias, ${ }^{92}$ and in rat brain during acute focal ischemia. ${ }^{32}$ Swann et al. ${ }^{56}$ postulated an ongoing excitotoxic injury of dendrites (dendrotoxicity) produced by excessive release of glutamate especially during seizures. In brain trauma there is also glutamateinduced citotoxicity, ${ }^{93}$ which supports Swann et al. ${ }^{94}$ hypothesis. According to Hasbani et al. ${ }^{94}$ the postsynaptic neuronal dendrite is selectively vulnerable to hypoxic-ischemic brain injury and glutamate receptor overactivation. Sodium, chloride, and water entry contribute acutely to excitoxicity dendritic injury, and calcium entry through NMDA receptors results in lasting structural changes in damaged dendrites. Lately Hasbani et al. ${ }^{94}$ expressed that in cerebral ischemia, neurons exposed to NMDA, kainite or oxygen-glucose deprivation suffer dendritic beading and lost of dendritic spines.

Lee et al. ${ }^{95}$ point out that $\mathrm{Ca}^{++}$-activated degradation of cytoskeletal proteins appears to be an early and important component of the postischemic response in hippocampal neurons, which can contribute to neuronal death. According to Tomimoto \& Yanagihara, ${ }^{97}$ the disintegration of microtubules and the resulting disruption of dendritic transport may contribute to subsequent development of delayed neuronal death. According Hayes et al. ${ }^{98}$ the traumatic brain injuries produce a widespread derangement to the neuronal cytoskeleton.

The molecular mechanism inducing the disintegration of cytoskeletal structures in traumatic brain injury could be due to loss of cytoskeletal proteins and microtubule associated protein 2 (MAP2), possibly by calpain-mediated proteolysis. ${ }^{86,99}$ Brain contusions also induce loss of both, MAP2 and neurogranin immunoreactivity. ${ }^{100}$

Mild and repetitive brain injuries may trigger cytoskeletal alterations related to neuronal degeneration and abnormal behaviour. ${ }^{101}$ Cytoskeletal disruption is a key pathological feature of Alzheimer's disease, characterized by dendritic degeneration..$^{5,102}$

Ultrastructural abnormalities of dendrites with damage of endoplasmic reticulum, mitochondrial lesion and disintegration of microtubules have been observed after chronic administration of valproate. ${ }^{36}$ Similar dendritic changes have been recently observed after fluid perfusion injury. ${ }^{103}$

Our findings suggest that anoxia e ischemia are the major pathogenetic mechanisms of dendritic swelling in the edematous human cerebral cortex associated to brain trauma, tumours and congenital malformations. ${ }^{83}$ Our observations on dendritic 
abnormalities in brain traumatic injuries revealed predominant beaded shape of swollen dendrites in comparison with those seen in brain malformations and tumors. The beaded dendrites exhibit disintegrated microtubules and microfilaments mainly at the dendritic varicosities. Derangement of dendritic cytoskeletal structures, mainly fragmentation and disintegration of microtubules and neurofilaments, are due to multifactorial factors, such as the shear stress induced by the traumatic agent, mitochondrial swelling, anoxic-ischemic condition of brain tissue, and protease activation..$^{24,87}$

In relationship with the damage of the limiting plasma membrane and the dendritic cytomembranes, such as mitochondrial, rough and smooth endoplasmic reticulum, lysosomal and Golgi membranes, could be due to increased permeability of lysosomes and release of acid and neutral proteases, ${ }^{104}$ interruption of dendritic transport, ${ }^{97}$ calpain-mediated spectrin breakdown, free radical release and lipid peroxidation, ${ }^{105-107}$ delayed phospholipid degradation by phospholipase activation, ${ }^{108}$ disruption of cytoskeletal structures, mitochondrial abnormalities and impaired production of ATP, elevation of intracellular calcium, ${ }^{87,99}$ activation of calcium-dependent proteolitic enzymes,${ }^{93}$ glutamate-induced neurotoxicity, ${ }^{31,107,110}$ protein aggregation after brain ischemia and reperfusion, ${ }^{111,112}$ intensity of shear forces in brain traumatic injury, increased intracranial pressure in moderate and severe edema. ${ }^{23,24}$ and release of lysosomal enzymes. ${ }^{113}$

\section{Dendritic abnormalities in brain tumors}

In relationship with the alteration of dendritic processes in brain tumors, such as in cystic craniopharyngioma and ependymoma, we have observed swollen dendrites with a granular proteinaceous aggregation in the dendroplasm, vacuolated rough and smooth endoplasmic reticulum canaliculi, dark and clear swollen mitochondria, disintegrated neurofilaments, scarce amount or absent of microtubules, presence of clathrin-coated vesicles and myelinlike figures ${ }^{24}$ (Figure 5). Swelling of dendrites with disarray of microtubules and neurofilaments and changes of surface morphology of dendritic spines were earlier reported by $\mathrm{Spacek}^{38}$ in epitumorous cerebral cortex. ${ }^{114,115}$

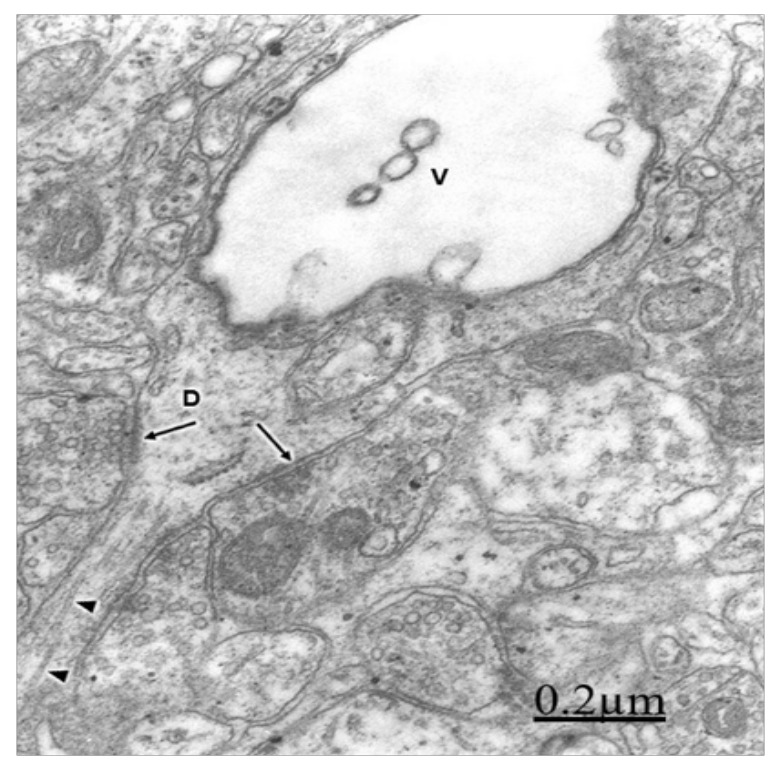

Figure 4 Brain traumas. Contusion and facture of frontal region. Left frontal cortex.

Beaded dendrite (D) showing a huge vacuole (V), microtubules (arrowheads) and activated asymmetric axodendritic synapses (long arrows) are seen in the initial dilated segment. $\times 60.000$

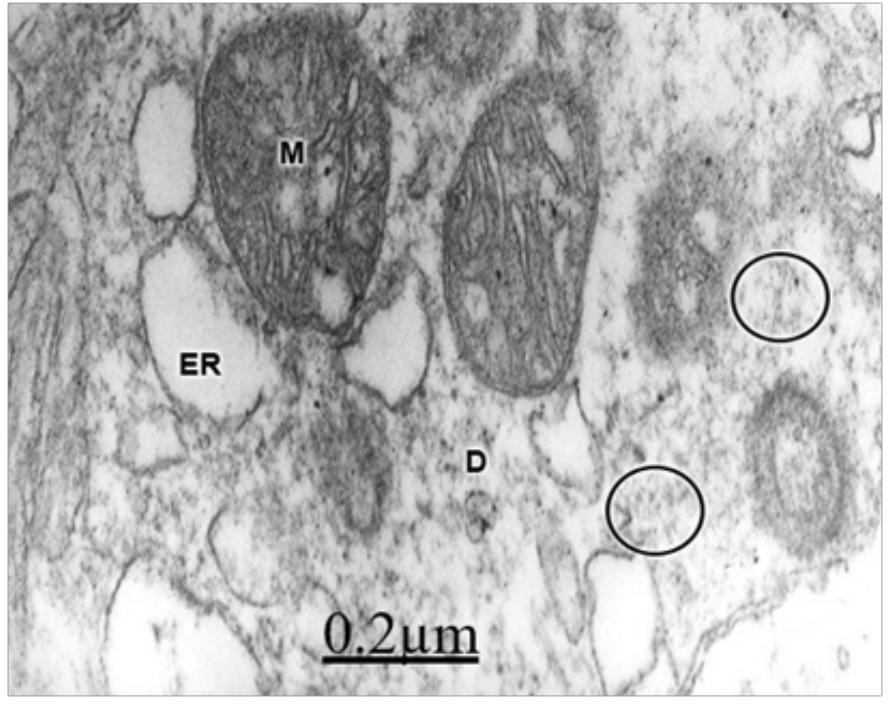

Figure 5 Cystic craniopharyngioma. Right fronto-temporal cortex. Severe edema.

Clear swollen dendrite (D) containing dark edematous mitochondria (M) and vacuolization of smooth and rough endoplasmic reticulum (ER). Microtubules and microfilaments appear disintegrated giving to the dendroplasm a granular aspect (circles). X 60.000 .

\section{Concluding remarks}

Swollen and beaded dendrites exhibit fragmentation of limiting plasma membrane, cytomembranes and cytoskeletal structures. The swollen dendrites show vacuolization, dense residual bodies, enlarged rough and smooth endoplasmic reticulum, and edematous clear and dark mitochondria. The multifactorial processes associated with brain edema and brain ischemia, such as calcium overload, activation of calcium-dependent proteolitic enzymes, protein aggregation, glutamate-induced neurotoxicity, release of lysosomal enzymes, deficit of ATP, stress oxidative and lipid peroxidation have been considered in relation with pathological dendritic changes. Dendrotoxicity due to brain edema and brain ischemia seems to be the fundamental pathogenetic mechanism underlying the dendritic damage.

\section{Acknowledgments}

None

\section{Conflicts of interest}

Author Declare there is no conflict so interest.

\section{References}

1. Scheibel AB, Tomiyasu U. Dendritic sprouting in Alzheimer's presenil dementia. Exp Neurol. 1978;60(1):1-8.

2. Buell SJ, Coleman PD. Dendritic growth in the aged human brain and failure of growth in senile dementia. Science. 1979;206(4420):854-856.

3. Konovalov GV, Chumasov EI, Krasnitska ZB, et al. Ultrastructural changes induced by a brief period of anoxia in cerebral cortex tissue culture. Arkh Patol. 1979;41(12):32-37.

4. Purpura DP. Pathobiology of cortical neurons in metabolic and unclassified dementias. Res Publ Assoc Res Nerv Ment Dis. 1979;43-68. 
5. Paula-Barbosa MM, Cardoso RM, Guimaraes ML, et al. Dendritic degeneration and regrowth in the cerebral cortex of patients with Alzheimer's disease. J Neurol Sci. 1980;45(1):129-134.

6. Goldstein B, Maxwell DS, Ellison G, et al. Dentritic vacuolization in the central nervous system of rats after long term voluntary consumption of ethanol. J Neuropathol Exp Neurol. 1983;42(5):579-589.

7. Helen P. Fine-structural and degenerative features in adult and aged human sympathetic ganglion cells. Mech Ageing Dev. 1983;232(2):161-175.

8. Sperk G, Lassmann H, Baran H, et al. Kainic acid induced seizures: neurochemical and histopathological changes. Neuroscience. 1983;10(4):1301-1315.

9. Tiller-Borcich JR, Urich H. Abnormal arborizations of Purkinje cell dendrites in Creutzfeldt-Jakob disease: a manifestation of neuronal plasticity? J Neurol Neurosurg Psychiatr. 1986;49(5):581-584.

10. Becker LE, Jagadha V. Structural adaptations of dendrites in the human brain during development and disease. In: Alan R Liss. Editor, New York, USA: Neural Plasticity: A Lifespan Approach; 1988. pp. 43-67.

11. Takada K, Becker LE, Chan F. Aberrant dendritic development in the human agyric cortex: a quantitative and qualitative Golgi study of two cases. Clin Neuropathol. 1988;7(3):111-119.

12. Takashima S, Becker LE, Chan F, et al. Golgi and computer morphometric analysis of cortical dendrites in metabolic storage disease. Exp Neurol. 1985;88(33):652-672.

13. Gallyas F, Zoltay G. An immediate light microscopic response of neuronal somata, dendrites and axons to non-contusing concussive head injury in the rat. Acta Neurophatol.1992;83(4):386-393.

14. Isacson O, Sofreniev MV. Neuronal loss or replacement in the injured cerebral neocortex induce extensive remodelling of intrinsic and afferent neural system. Exp Neurol. 1992;117(2):151-175.

15. Belichenko PV, Sourander P, Malmgren K, et al. Dendritic morphology in epileptogenic cortex from TRPE patients, revealed by intracellular Lucifer Yelow microinjection and confocal laser scanning microscopy. Epilepsy Res. 1994;18(3):233-247.

16. Kolb B, Gibb R, van der Kooy D. Neonatal frontal cortical lesions in rats alter cortical structure and connectivity. Brain Res. 1994;645(1-2):85-97.

17. O'Hanlon GM, Lowrie MB. Nerve injury in adult rats causes abnormalities in the motonneuron dendritic field that differ from those seen following neonatal nerve injury. Exp Brain Res. 1995;103(2):243-250.

18. Belichenko PV, Dahlstrom A. Confocal laser scanning microscopy and 3-D reconstruction of neuronal structures in human brain cortex. Neuroimage. 1995;2(3):201-207.

19. Mathew P, Bullock R, Graham DI, et al. A new experimental model of contusion in the rat. Histopathological analysis and temporal patterns of cerebral blood flow disturbance. J Neurosurg. 1996;85(5):860-870.

20. Akulinin VA, Stepanov SS, Semchenko VV, et al. Dendritic changes of the pyramidal neurons in layer $\mathrm{V}$ of sensory-motor cortex of the rat brain during the postresuscitation period. Resuscitation. 1997;35(2):157-164.

21. Anderton BH, Callahan L, Coleman P, et al. Dendritic changes in Alzheimer's disease and factors that may underlie these changes. Prog Neurobiol.1998;55(6):595-609.

22. Kerr SJ, Armati PJ, Guillemin GJ, et al. Chronic exposure of human neurons to quinolinic acid results in neuronal changes consistent with AIDS dementia complex. AIDS. 1998;12(4):355-363.

23. Castejón OJ, Valero C, Diaz M. Synaptic degenerative changes in human traumatic brain edema. An electron microscopic study of cerebral cortical biopsies. J Neurosurg Sci. 1995;9:47-65.
24. Castejón OJ, Valero C, Diaz M. Light and electron microscope study of nerve cells in traumatic oedematous human cerebral cortex. Brain Injury. 1997;11(5):363-388.

25. Castejón OJ. Electron microscopic analysis of cortical biopsies in patients with traumatic brain injuries and dysfunction of neurobehavioral system. J Submicrosc Cytol Pathol. 1998;30:145-156.

26. Castejón OJ. Ultrastructural pathology of Golgi apparatus of nerve cells in human brain edema associated to brain congenital malformations, tumours and trauma. J. Submicrosc Cytol Pathol. 1999;31(2):203-213.

27. Benitez-Bribiesca L, De La Rosa-Alvarez I, Mansilla-OlivaresA. Dendritic spine pathology in infants with severe protein-calorie malnutrition. Pediatrics. 1999;104(2):e21.

28. Kaufmann WE, Moser HW. Dendritic anomalies in disorders associated with mental retardation. Cerebr Cortex. 2000;10(10):981-991.

29. Semchenko VV, Stepanov SS, Nikel AE, et al. Postischemic reorganization of dendritic architectonics of the hippocampal CA3 region in albino rats predisposed to seizures. Morfologiia. 2000;118(6):25-30.

30. Kreibel RM, Mc Allister JP. Pathology of the hippocampus in experimental feline infantile hydrocephalus. Neurol Res. 2000;22(1):29-36.

31. Swann JW, Al-Noori S, Jian GM, et al. Spine loss and other dendritic abnormalities in epilepsy. Hippocampus.2000;10(5):617-625.

32. Liu KF, Li F, Tatlisuma K, et al. Regional variations in the apparent diffusion coefficient and the intracellular distribution of water in rat brain during acute focal ischemia. Stroke. 2001;32(8):1897-1905.

33. Hasbani MJ, Schlief ML, Fisher DA, et al. Dendritic spine lost during glutamate receptor activation reemerges at original sites of synaptic contact. J Neurosci. 2001;21(7):2393-2403.

34. Di Rocco F, Giannetti S, Gaglini, P, et al. Dendritic anomalies in a freezing model of microgyria: a parametric study. Pediatr Neurosurg. 2001;34(2):57-62.

35. Di Rocco F, Giannetti S, Gaglini P, et al. Dendritic architecture of corticothalamic neurons in a rat model of microgyria. Childs Nerv Syst. 2002;18(12):690-693.

36. Sobaniec-Lotowska ME. Ultrastructure of Purkinje cell perikarya and their dendritic processes in the rat cerebellar cortex in experimental encephalopathy induced by chronic application of valproate. Int $J$ Exp Pathol. 2001;82(6):337-348.

37. Broadbelt K, Byne W, Jones LB. Evidence for a decrease in basilar dendrites of pyramidal cells in schizophrenic medial prefrontal cortex. Schizophr Res. 2002;58(1):75-81.

38. Fiala JC, Spacek J, Harris KM. Dendritic spine pathology: cause or consequence of neurological disorders? Brain Res Brain Res Rev. 2002;39(1):29-54.

39. Castejón OJ, Zavala M, Sanchez ME, et al. A light and electron microscopic study of oedematous human cerebral cortex in two patients with post-traumatic seizures. Brain Injury. 2002;16(4):331-346.

40. Galvez R, Gopal AR, Greenough WT. Somatosensory cortical barrel dendritic abnormalities in a mouse male of the fragile $\mathrm{X}$ mental retardation syndrome. Brain Res. 2003;971(1):83-89.

41. Dieni S, Rees S. Dendritic morphology is altered in hippocampal neurons following prenatal compromise. J Neurobiol. 2003;55(1):41-52.

42. Judas M, Rasin MR, Kruslin B, et al. Dendritic overgrowth and alterations in laminar phenotypes of neocortical neurons in the newborn with semilobar heloprosencephaly. Brain Dev. 2003;25(1):32-39.

43. Chung RS, Vickers JC, Chuah MI, et al. Metallothionein-IIA promotes initial neurite elongation and postinjected reactive neurite growth and facilitates healing after focal cortical brain injury. $J$ Neurosci. 2003;23(8):3336-3342. 
44. Benavides-Piccione R, Ballesteros-Yanez I, De Lagran MM, et al. On dendrites on Down sy and DS murine models: a spini way to learn. Progr Neurobiol. 2004;74(2):111-126.

45. Alrred RP, Jones TA. Unilateral ischemic sensorimotor damage in female rats: forelimb behaviour effects and dendritic structural plasticity in the contralateral homotipic cortex. Exper Neurol. 2004;190(2):433-445.

46. Peyghambari F, Valojerdi MR, Tiraihi T. A morphomoetric study on the early stages of dendritic changes in the axotomized motoneuron of the spinal cord in newborn. Neurol Res. 2005;27(6):586-590.

47. Flores G, Alquicer G, Silva-Gomez AG, et al. Alterations in dendritic morphology of prefrontal cortical and nucleus accumbens neurons in postpubertal rats after neonatal excitotoxic lesions of the ventral hippocampus. Neuroscience. 2005;133(2):463-470.

48. Ruan YW, Zou B, Fan I, et al. Dendritic plasticity of CA1 pyramidal neurons after transient global ischemia. Neuroscience. 2006;140(1):191-201.

49. Buell SJ, Coleman PD. Dendritic growth in the aged human brain and failure of growth in senile dementia. Science. 1979;206(4420):854-856.

50. Frydl V, Zavodska $\mathrm{H}$. Changes in dendrites in disease and aging. Zeitsc Anat. 1989;44(6):345-358.

51. Marin-Padilla M. Pyramidal cell abnormalities in the motor cortex of a child with Down's syndrome: A Golgi study. J Comp Neurol. 1976;167(1):63-82.

52. Huttenlocher PR. Dendritic development in neocortex of children with mental defect and infantile spasms. Neurology. 1974;24(3):203-210.

53. Machado-Salas JP. Abnormal dendritic patterns and aberrant spine development in Bourneville's disease-A Golgy survey. Clin Neuropathol. 1984;3(2):52-58.

54. Zecevic N, Rakic P. Differentiation of Purkinje cells and their relationship to other components of developing cerebellar cortex in man. J Comp Neurol. 1976;167(1):27-48.

55. Vaquero J, Oya S, Cabezudo JM, et al. Morphological study of human epileptic dendrites. Neurosurgery. 1982;10(6):720-724.

56. Swann JW, Al-Noori S, Jian GM, et al. Spine loss and other dendritic abnormalities in epilepsy. Hippocampus.2000;10(5):617-625.

57. Castejón J, Arismendi GJ. Morphological changes of dendrites in the human edematous cerebral cortex. A transmission electron microscopic study. J Submicrosc Cytol Pathol. 2003;35(4):395-413.

58. Probst A, Basler V, Bron B, et al. Neuritic plaques in senile dementia of Alzheimer type: a Golgi analysis in the hippocampal region. Brain Res. $1983 ; 268(2): 249-254$

59. Nakamura S, Akiguchi I, Kameyama M, et al. Age-related changes of pyramidal cell basal dendrites in layers III and V of human motor cortex: a quantitative Golgi study. Acta Neuropathol. 1985;65(3-4):281-284.

60. Graveland GA, Williams RS, Difiglia M. Evidence for degenerative and regenerative changes in neostriatal spiny neurons in Huntington's disease. Science. 1985;227(4688):770-773.

61. Blandpied TA, Scott DB, Ehlers MD. Age-related regulation of dendritic endocytosis associated with altered clathrin dynamics. Neurobiol Aging. 2002;24(8):1095-1104.

62. Works SJ, Wilson RE, Wellman CL. Age-dependent effect of cholinergic lesion on dendritic morphology in rat frontal cortex. Neurobiol Ageing. 2004;25(7):963-974.

63. Vega E, Gómez-Villalobos M, De J, et al. Alteration on dendritic morphology of pyramidal neurons from the prefrontal cortex of rats with renovascular hypertension. Brain Res. 2004;17(1):112-118.
64. Wedzony K, Fijal K, Mackoviac M. Alterations in the dendritic morphology of prefrontal pyramidal neurons in the adult rat after blockade of NMDA receptors in the postnatal period. Brain Res. 2005;1062(1-2):166-170.

65. Rernsing N, Ouyang Y, Yang XF, et al. In vivo imaging of dendritic spines during electrographic seizures. Ann Neurol. 2005;58(6):888-898.

66. Radley JJ, Rocher AB, Janssen WG, et al. Reversibility of apical dendritic retraction in the rat medial prefrontal cortex following repeated stress. Exper Neurol. 2005;193(1):196-203.

67. Brown SM, Henning S, Wellman CL. Mild short-term stress alters dendritic morphology in rat medial prefrontal cortex. Cerebr Cortex. 2005;15(11):1714-1722

68. Zaja-Milatovics S, Milatovic D, Schantz AM, et al. Dendritic degeneration in neostriatal medium spiny neurons in Parkinson disease. Neurology. 2005;64(3):545-547.

69. Ishikura N, Clever JL, Bouzamondo-Benrstein E, et al. Notch-1 activation and dendritic atrophy in prion disease. Proc Nat Acad Sci USA. 2005;102(3):886-891

70. Dierssen M, Ramakers GJ. Dendritic pathology in mental retardation: from molecular genetic to neurobiology. Genes Brain Behav. 2008;5(Suppl 2):48-60.

71. Shimada A1, Tsuzuki M, Keino H, et al. Apical vulnerability to dendritic retraction in prefrontal neurons of ageing SAM10 mouse: a model of cerebral neurodegeneration. Neuropathol Appl Neurobiol. 2006;32(1):114.

72. Hoskison MM, Shuttleworth CW. Microtubule disruption, not calpaindependent loss of MAP2, contributes to enduring NMDA-induced dendritic dysfunction in acute hippocampal slices. Exp Neurol. 2006;202(2):302-312.

73. Dlugos CA. Ethanol-related increases in degenerating bodies in the Purkinje neuron dendrites of aging rats. Brain Res. 2008;1221:98-107.

74. Baloyannis SJ, Costa V, Mauroudis I, et al. Dendritic and spinal pathology in the acoustic cortex in Alzheimer's disease: morphological and morphometric estimation by Golgi technique and electron microscopy. Acta Otolaryngol. 127(4):351-354.

75. Greenwood SM, Connolly CN. Dendritic and mitochondrial changes during glutamate excitotoxicity. Neuropharmacology. 2007;53(8):891898.

76. Shansky RM, Morrison JH. Stress-induced dendritic remodeling in the medial prefrontal cortex: effects of circuit, hormones and rest. Brain Res. 2009; 1293:108-113.

77. Liu M, Duggan J, Salt TE, et al. Dendritic changes in visual pathways in glaucoma and other neurodegenerative conditions. Exp Eye Res. 2011;92(4):244-250.

78. Deng YP, Reiner A. Cholinergic interneurons in the Q140 knockin mouse model of Huntington's disease: Reductions in dendritic branching and thalamostriatal input. J Comp Neurol. 2016;524(17):3518-3529.

79. Lopes S, Teplytska L, Vaz-Silva J, et al. Tau Deletion Prevents StressInduced Dendritic Atrophy in Prefrontal Cortex: Role of Synaptic Mitochondria. Cereb Cortex. 2017;27(4):2580-2591.

80. Nava N, Treccani G, Alabsi A, et al. Temporal dynamics of acute stressinduced dendritic remodeling in medial prefrontal cortex and the protective effect of Desipramine. Cereb Cortex. 2017;27(1):694-705.

81. Saberi S, Stauffer JE, Jiang J, et al. Sense-encoded poly-GR dipeptide repeat proteins correlate to neurodegeneration and uniquely co-localize with TDP-43 in dendrites of repeat-expanded C9orf72 amyotrophic lateral sclerosis. Acta Neuropathol.135(3):459-474. 
82. Castejon OJ. Transmission electron microscope study of human hydrocephalic cerebral cortex. J Submicrosc Cytol Pathol. 1994;26(1):2939.

83. Castejón OJ, de Castejón HV. Structural patterns of injured mitochondria in human oedematous cerebral cortex. Brain Inj. 2004;18(11):1107-1126.

84. McAllister JP 2nd, Maugans TA, Shah MV, et al. Neuronal effects of experimentally induced hydrocephalus in newborn rats. J Neurosurg. 1985;63(5):776-783.

85. Harris NG, McAllister JP, Conaughty JM, et al. The effect of inherited hydrocephalus and shunt treatment on cortical pyramidal cell dendrites in the infant H-Tx rat. Exp Neurol. 141(2):269-279.

86. Posmantur RM, Kampfl A, Taft WC, et al. Diminished microtubuleassociated protein 2 (MAP2) immunoreactivity following cortical impact brain injury. J Neurotrauma. 1996b;13(3):125-137.

87. Saito N, Chang C, Kawai K, et al. Role of neuroexcitation in development of blood-brain barrier and oedematous changes following cerebral ischaemia and traumatic brain injury. Acta Neurochir Suppl (Wien). 1990;51:186-188.

88. Nakayama Y, Aoki Y. Mechanism responsible for the formation of focal swellings on injured neuronal processes using a novel in vitro model of axonal injury. Forensic Sci Int. 2000;113:245-249.

89. Nakayama Y, Aoki Y, Niitsu H. Studies on the mechanisms responsible for the formation of focal swellings on neuronal processes using a novel in vitro model of axonal injury. J Neurotrauma. 2001;18L545-554.

90. Nag S. Ultrastructural studies of endothelium in NMDA-induced excitotoxicity. In: Globus M et al., editors. The Role of Neurotransmitters in Brain Injury. New York: Plenum Press. 1992. p. 271-277.

91. Nag S. Vascular changes in the spinal cord in N-methyl-D-aspartateinduced excitotoxicity: morphological and permeability studies. Acta Neuropathol. 19922b;84(5):471-477.

92. Meredith GE, De Souza IE, Hyde TM, et al. Persistent alterations in dendrites, spines, and dynorphinergic synapses in the nucleus accumbens shell of rats with neuroleptic-induced dyskinesias. $J$ Neurosci. 2000;20(20):7798-7806.

93. Hayes RL. Neurochemical changes in traumatic brain injury. In Catastrophic Brain Injury. In: Levin HS et al., editors. Oxford University Press. New York, 1996. p. 183-207.

94. Hasbani MJ, Hyre KL, Faddis BT, et al. Distinct roles for sodium, chloride, and calcium in excitotoxic dendritic injury and recovery. Exp Neurol. 1988;154(1):241-258.

95. Swann JW, Al-Noori S, Jian GM, et al. Spine loss and other dendritic abnormalities in epilepsy. Hippocampus. 2000;10(5):617-625.

96. Lee KS, Frank S, Vanderklish P, et al. Inhibition of proteolysis protects hippocampal neurons from ischemia. Proc Natl Acad Sci USA. 1991;88:7233-7237.

97. Tomimoto H, Yanagihara T. Golgi electron microscopic study of the cerebral cortex after transient cerebral ischemia and reperfusion in the gerbil. Neuroscience. 1994;63(4):957-967.

98. Hayes RL, Yang K, Whitson JS, et al. Cytoskeletal derangements following central nervous system injury: modulation by neurotrophic gene transfection. J Neurotrauma. 1995;12(5):933-941.
99. Posmantur RM, Kampfl A, Liu SJ, et al. Cytoskeletal derangements of cortical neuronal processes three hours after traumatic brain injury in rats: an immunofluorescence study. $J$ Neuropathol Exp Neurol. 1996a;55(1):68-80.

100. Li GL, Farooque M, Lewen A, et al. MAP2 and neurogranin as markers for dendritic lesions in CNS injuries. An immunohistochemical study in the rat. APMIS. 2000;108(2):98-106.

101. Kanayama G, Takeda M, Niigawa H, et al. The effects of repetitive mild brain injury on cytoskelatal protein and behavior. Methods Find Exp Clin Pharmacol. 1996;18(2):105-115.

102. McKee AC, Kowall NW, Kosik KS. Microtubular reorganization and dendritic growth response in Alzheimer's disease. Ann Neurol. 1989;26(5):652-659.

103. Ip EY, Giza CC, Griesbach GS, et al. Effects of enriched environment and fluid percussion injury on dendritic arborization within the cerebral cortex of the developing rat. $J$ Neurotrauma. 2002;19(5):573-585.

104. Auer L. A contribution to the pathophysiology of post-traumatic brain oedema. Wien Klin Wochenschr. 1975;87:556-560.

105. Bondy SC. Evaluation of free radical-initiated oxidant even within the nervous system: In: Paradigms of Neural Injury. Perez-Polo JR editor. Academic Press. New York, 1996. p. 243-256.

106. Jackson GR, Perez-Polo JR. Paaradigms for study of neurotrophin effects in oxidant injury. In: Paradigms of Neuroal Injury. Perez-Polo JR editor. Academic Press. New York, USA. 1996. p. 1-25.

107. Dugan LL, Choi DW. Hipoxic-ischemic brain injury and oxidative stress. In Basic Neurochemistry. Siegel GJ et al. editors. Lipincott-Raven Pub. Philadelphia, 1998. p. 711-729.

108. Homayoun P, Rodriguez, De Turco, et al. Delayed phospholipid degradation in rat brain after traumatic brain injury. $J$ Neurochem. 1997;69(1):199-205.

109. Ikeda J, Nagashima G, Saito J. Putative neuroexcitation in cerebral ischemia and brain injury. Stroke. 1990;21(11Suppl):65-70.

110. Morley P, Tauskela JS, Hakim AM. Calcium overload. In: Walz W, editor, Cerebral Ischemia. Molecular and cellular pathophysiology. New Jersey, USA: Humana Press; 1999. pp. 69-104.

111. $\mathrm{Hu} \mathrm{BR}$, Janelidze S, Ginsberg MD, et al. Protein aggregation after focal brain ischemia and reperfusion. $J$ Cereb Blood Flow Metab. 2001;21(7):865-875.

112. Hu BR, Martone ME, Jones YZ, et al. Protein aggregation after transient cerebral ischemia. J Neurosci. 20(9):3191-3199.

113. Ditaranto-Desimone K, Saito M, Tekirian TL, Saito M, et al. Neuronal endosomal/lysosomal membrane destabilization activates caspases and induces abnormal accumulation of the lipid secondary messenger ceramide. Brain Res Bull. 2003;59(6):523-531.

114. Fredriksson K, Kalimo H, Nordborg C, ET AL. Nerve cell injury in the brain of stroke-prone spontaneously hypertensive rats. Acta Neurophatol. 1988;76:227-237.

115. McKee AC, Kowall NW, Kosik KS. Et al. Microtubular reorganization and dendritic growth response in Alzheimer's disease. Ann Neurol. $1989 ; 26(5): 652-659$. 